\title{
Attitudes towards Alcohol Use among University Students in Sri Lanka: Application of the Theory of Planned Behaviour
}

\author{
W.S. Chandrasekara ${ }^{1}$ \\ ${ }^{1}$ Institute of Human Resource Advancement \\ University of Colombo \\ SRI LANKA \\ sagara@ihra.cmb.ac. $\mathrm{lk}^{1}$
}

\begin{abstract}
Alcohol use is regarded as a health issue among university students, which presently has a high occurrence. The objective of this research is to investigate the determinants of intentions toward Alcohol use among university students. Based on the Theory of Planned Behaviour (TPB), it is hypothesized that favourable attitude, subjective norms, and lack of behavioural control will be positively and significantly associated with intention towards alcohol use and alcohol use behaviour among university students in Sri Lanka. A questionnaire was developed based on the TPB domains. Separately, alcohol use behaviour questionnaire was developed. Both were circulated among university students through google forms and social media. It was received a total number of 320 completed questionnaires from students. Coefficients path analyses of study variables, attitude $(b=0.34)$, subjective norms $(b=0.28)$ indicate a significant effect on the intention to use alcohol at the $1 \%$ level $\left(\mathrm{H}_{1} \& \mathrm{H}_{2}\right)$. However, PBC does not indicate a significant impact on intention $(b=0.03)$ to use alcohol $\left(\mathrm{H}_{3}\right)$. Furthermore, Intention towards alcohol use is positively and significantly correlated with alcohol use behaviour $\left(b=0.31, H_{4}\right)$. This research validates the possibility of TPB in studying the behavioural intention and actual behaviour in a different social context. These findings will be important policy implications, policy-makers who wish to reduce alcohol use among university students can introduce interventions targeting to reduce positive attitudes towards alcohol use intention and favourable subjective norms towards reducing alcohol use intention. Correspondingly, policymakers can propose educational awareness programs to increase the PBC among university students relating alcohol use intention and behaviour. The results indicate the effectiveness of diverse approaches to alcohol reduction programs.
\end{abstract}

Keywords: Alcohol use intention, Attitudes, University Students, Theory of planned behaviour, Sri Lanka

\section{INTRODUCTION}

Although policies and laws control alcohol use among adolescents, it remains as one of the most common problems among university students.
During the last few decades, university administrations articulated concern about increasing levels of alcohol use by university students (Carey, ScottSheldon, Carey, Kelly, \& DeMartini, 2007). Drinking alcohol among young people is a universal issue. Alcohol 
use is a very vital factor for illness and social, and other damage globally (Beaglehole \& Bonita , 2009). Therefore, reducing alcohol use among university students is the main challenge faced by the government's alcohol risk reduction programs. It has been acknowledged that the alcohol use by university students support directly and indirectly in the increase of physical, emotional and social damagers (Gutiahr, Gmel, \& Rehm, 2001). University students consume more alcohol quantities at a time than their peers (Gill, 2002). Drinking alcohol by university students intensify the risk of social and academic difficulties as well as accidental injury, fighting and death (Wechsler, et al., 2002). Alcohol consumption is the most serious problem in university life worldwide (Davoren, Demant, Shiely, Ivan, \& Perry, 2016). The worldwide alcohol use of persons over 15 years old is 6.2 litres of alcohol every year averagely (WHO, Global Status Alcohol Report, 2014). Total alcohol per capita (15 year and above) consumption, drinkers only (in litres of pure alcohol) for male 18.9 litres, for female 6.7 litres, and both sexes 14.9 litres in 2016 (WHO, 2018). The economic cost of excessive alcohol use is considerable worldwide, for instance, in the UK the cost of alcohol-related damage has been assessed as $£ 3$ billion per year (Balakrishnan, Allender, \& Scarborough, 2009). The predicted current value of present and future financial burden of the alcohol-related problems for Sri Lanka in 2015 was USD 885.86 million, $1.07 \%$ of the GDP of that year (Ranaweera, et al., 2018). Alcohol use is correlated with harmful consequences such as accidents, reduced educational performance (Kuntsche, Kuntsche, Thrul, \& Gmel, 2017). The impact of harmful outcomes of alcohol use is not only for drinkers but also for other people include road accidents and life losses, forcefulness, violence, and crime, damage to domestic violence and harm such as mental stress and distress, agony and grief, separation, and divorce, poverty (Kuntsche, Kuntsche, Thrul, \& Gmel, 2017; Anderson \& Baumberg, 2006).

Being with heavy drinking peers is significantly correlated with the amplified use of alcohol among student (Cheng \& Lo, 2015). The multiple disadvantage theory explores how alcohol use is correlated with the setting of disadvantages, such as social-structural factors, aspects of social exclusion and factors related to mental health (Lo, Howell, \& Cheng, 2013). The model describes risk factors of alcohol use among students, for example, poor socioeconomic status of students and their maladaptive reactions to persistent stress (Poonawalla, Kendzor, Owen, \& Caughy, 2014). To introduce successful alcohol use reduction interventions, it is essential to comprehend the students' present alcohol use, and what would best influence to reduce positive attitudes and intention towards alcohol use (Hasson, 2010). Thus, this research will be important to comprehend the determinants of alcohol use among university students thereby introduce successful alcohol use reduction interventions. 


\subsection{Alcohol Use among University Students}

According to the National alcohol use prevalence survey in Sri Lanka (2014), conducted in 2014 reported that $39.6 \%$ males are present alcohol users whereas only $2.4 \%$ females are present alcohol user in Sri Lanka (Somatunga, Ratnayake, Wijesin, Yapa, \& Cooray, 2014). Prevalence of alcohol use among Sri Lankans is increasing and present alcohol users in urban areas $(32.9 \%)$ are higher than rural areas (20.8\%) in Sri Lanka (De Silva, Samarasinghe, \& Gunawardena, 2009). Many types of illicit substances such as, Betel chewing with tobacco (28.48\% males and $10.44 \%$ females), Barbul, Madana Modaka, and cough syrups were used by schoolchildren (Liyanage, et al., 2015). A noteworthy higher percentage of male population than female population showed positive attitudes toward the alcohol use, male, $27 \%$,and female $7 \%$ (Perera \& Mohammad, 2004). The alcohol consumption rates and related consequences suffered among college students are well documented (OsterAaland \& Neighbors, 2007). University students use alcohol in a different environment (Oster-Aaland $\&$ Neighbors, 2007). The freedom that students have to receive alcohol use experience and free access to alcohol for university students is greater than in early periods (Harpin, BrooksRussell, Ma, James, \& Levinson, 2018). Freedom and easy access to alcohol are the main factors for the intention to use alcohol (Warren, Smalley, \& Barefoot, 2015). Alcohol use is most common among university students (Oster-Aaland \& Neighbors, 2007). According to Yurasek, et al
(2017), extreme level of alcohol use among university students can be a dangerous issue relating to social and behavioural negative impact. University students who engage in alcohol use indicate a greater rate of non-attendance, reduced test results, and nor performing school work well (White \& Hingson, 2013). According to Carpenter et al., (2008), University setting itself encourage alcohol use. University students are in a transitional period. This transition leads them to experience the extensive transformation in social activities, leisure time, socialization, and involve in risky behaviours such as alcohol use (Arria, et al., 2010). Alcohol use is a very common behaviour among male and female Sri Lankan graduates. However, it is a highly frequent among male undergraduate $(30.5 \%)$ than female undergraduates $(3.5 \%)$ (Perera \& Mohammad, 2004). Same study found that third year Sri Lankan university students tend to use more alcohol compaired to other years, perhaps it may due to socialization process and stress. Third year students will have to find jobs after their gratuation and they may have to consider about job security, furure chalangers, and uncertainity about their future and may encorrage them to use alcohol (Perera \& Mohammad, 2004). Sri Lankan cultural norms and values do not encourage alcohol use by adults, specially students. This may have an influence on less prevalence of alcohol use among undergraduates. However, sri lankan university students may tend to use alcohol because of adapting to the new university environment, and being away and detached from their families (Perera \& Mohammad, 2004). 


\subsection{The Theory of Planned Behaviour (TPB) and Alcohol Use}

The Theory of Planned Behaviour (TPB) (Ajzen, The theory of planned behavior, 1991), has been used to comprehend the health-related conduct in many studies (Fishbein \& Ajzen, 2010), drinking intentions and behaviour among young people (Norman, Bennett, \& Lewis, 1998; Cooke, Sniehotta, \& Schüz, 2007; Zhao, White, Young, \& Obst, 2018). The TPB is an extension model of the theory of reasoned action (Ajzen \& Fishbein, 1980). TPB predicts that if a person has a solid intention to involve in behaviour, then there is a higher possibility of performing the behaviour. The intention and behaviour are predicted by three components; 1, Attitude, individual's assessment of the behaviour, 2, Subjective Norms (SN), perception of the social pressure to engage in the particular behaviour, and 3, Perceived behavioural control (PBC), their belief about the ability to carry out the particular behaviour. There is consistent evidence that intentions are predicted by attitudes and subjective norms, and then, intentions predict the particular behaviour. According to Ajzen (2011), intention is a person's willingness to accomplish a given behaviour. On the other hand, the pattern of $\mathrm{PBC}$ findings are more mixed (Norman \& Conner, 2006). For instance, $\mathrm{PBC}$ is negatively associated to frequency of alcohol use (Norman et al., 1998; Norman \& Conner, 2006), but in other studies, $\mathrm{PBC}$ is positively associated to alcohol use (McMillan \& Conner, 2003).
Numerous studies of attitudebehaviour relations have demonstrated that people's attitudes are often incongruent with their behaviour (Fishbein \& Ajzen, Belief, attitude, intention, and behavior: An introduction to theory and research, 1975). This disparity allows researchers to develop theories that can explain well or more accurately. TPB is one of such greatest theory developed by Ajzen (1991). Social influence on alcohol use is correlated largely with attitudes toward alcohol use and alcohol use behaviour (Perkins, 2002). University students mostly think that their classmates take alcohol more quantities in a time and more regularly than themselves (Baer \& Carney , 1993). A comprehensive analysis of non-drinkers discovered that the peers' attitudes toward alcohol consumption considerably forecasted students' drinking behaviour. Those who did not have colleagues that prevented them from alcohol use, they were three-fold more likely to use alcohol at the university than students who had peers with undesirable attitudes toward alcohol use in the university (Lo and Globetti 1993). All the above three dimensions are believed to straightforwardly influence on intention and thereby behaviour.

The TPB has been developed as one of the most powerful and important behavioural involvement models, the model is given as follows; 


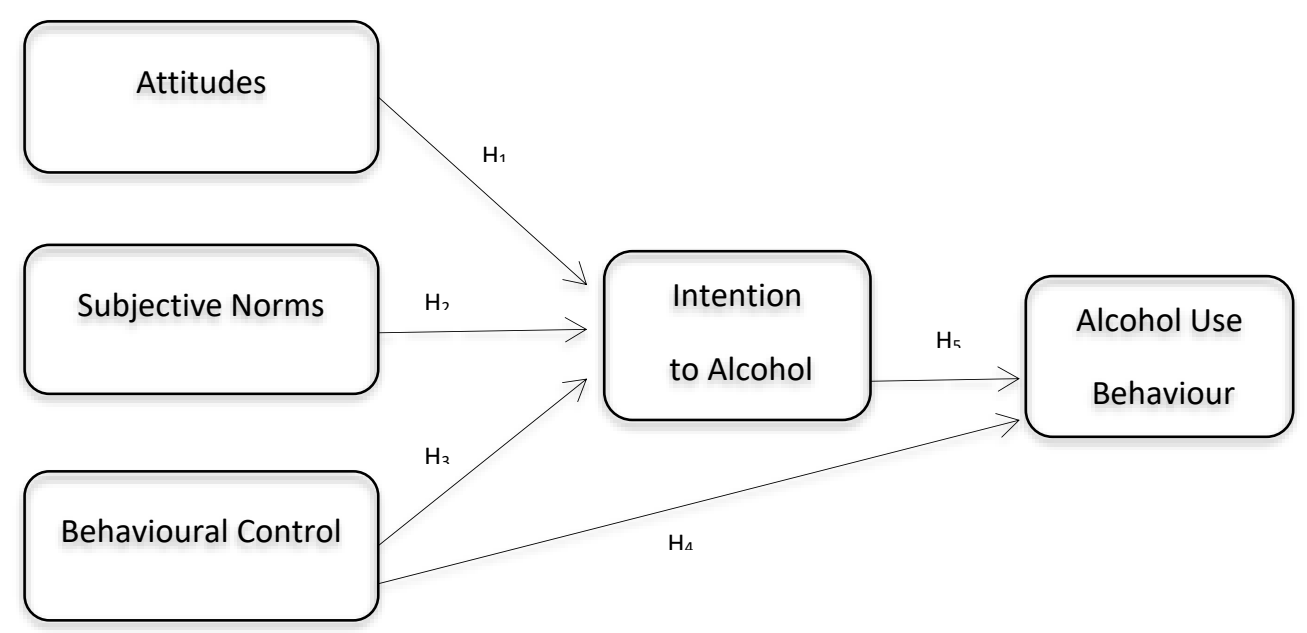

Figure 1. Study Overview based on the TPB (Ajzen, 1991)

The TPB has been fruitfully applied to comprehend main beliefs against different behavioural accomplishments among university undergraduates, including students' alcohol consumption (Cooke, Dahdah, Norman, \& French, 2014).

$\mathrm{H}_{1}$ : Positive Attitude towards alcohol use is positively and significantly related to alcohol use intention.

$\mathrm{H}_{2}$ : Positive Subjective Norm towards alcohol use is positively and significantly related to alcohol use intention.

$\mathrm{H}_{3}$ : Positive Perceived Behavioural Control towards alcohol use is positively and significantly related to alcohol use intention.

$\mathrm{H}_{4}$ : Positive Perceived Behavioural Control towards alcohol use is positively and significantly related to alcohol use behaviour.
$\mathrm{H}_{5}$ : Intention of alcohol use is positively and significantly related to alcohol use behaviour.

\section{METHOD AND MEASURES}

\subsection{Participants}

Google forms and social media survey was carried out with Sri Lankan government university students. The Theory of Planned Behaviour questionnaire and the alcohol use behaviour questionnaire were circulated through google forms and social media based on the above measurements of variables. Data collection was carried out from 15th January to 15th May 2018. It was received a total number of 340 completed questionnaires from both male and female students. However, it was received only 20 completed questionnaires from female students who had never used alcohol. 
Therefore, female students were excluded from the analysis and 320 male students' questionnaires were analysed.

\subsection{Background information}

Few background questions were included to collect demographic data, such as Sector that they have come from, urban $(\mathrm{n}=133,41.5 . \%)$, rural $(n=167,52.2 \%)$ estate $(n=20,6.3 \%)$, class year, (First year, second year, third year, and fourth year) Religion (Buddhist, $\mathrm{n}=278,86.9 \%$, Hindu $\mathrm{n}=$ $18,5.6 \%$, Muslims $\mathrm{n}=6,1.9 \%$, Catholic $\mathrm{n}=10,3.1 \%$, Christian $\mathrm{n}=8$, $2.5 \%$ ), and ethnicity (sinhala $\mathrm{n}=295$, $92.2 \%$, tamil $\mathrm{n}=21,6.6 \%$, moor $\mathrm{n}=6$, $1.8 \%$ ). Respondents were asked to mention the age of their first alcohol intake.

\subsection{Attitudes}

Positive attitudes towards alcohol use were measured based Drinking Motives Questionnaire (DMQ) developed by Cooper (1994). This 20item DMQ includes three subscales. Subscales and the measurements for each subscale were as; 1) Coping, "to forget your worries"; 2) Enhancement, "Because you like the feeling"; 3) Social, "To be sociable". It was measured based on a 5-point Likert scale.

\subsection{Subjective Norms (SN)}

Favourable subjective norms towards alcohol use measured using a question based on prior research (Zimmermann $\&$ Sieverding, 2010). Acceptance of alcohol use by parents, friends and important others was measured. The questions included were; 1) How do you think your parents, friends, and important others would react if they knew that you drink alcohol?. It was measured based on a 5-point Likert scale $1=$ disapprove to $5=$ approve

\subsection{Perceived Behavioural Control (PBC)}

PBC was measures based on the Rutgers Alcohol Problem Index (RAPI) developed by White \& Labouvie, 1989). This scale deals with the incapability of rejecting alcohol. The RAPI consist of 23 elements. Four elements cover the lack of behavioural control. They were asked following questions to measure PBC; 1) Did you feel that you want more alcohol than you took to have the same effect; 2) Did you attempt to regulate your alcohol intake by controlling to drink only at confident intervals of the day or in confident places; 3) Did you try to reduce or stop drinking; 4) Have you been drinking when you were told by yourself not to drink?. It was measured based on the 5-point Likert scale.

\subsection{Drinking intentions}

Drinking intention to use alcohol was measured based on two questions in prior research (Zimmermann \& Sieverding, 2010). They are; Do you have the intention to be drunken within the next 30 days, and How possibly you are going to be drunk within the next 30 days. It was measured based on a 5-point Likert scale (very unlikely-very likely). 


\subsection{Drinking behaviour}

Two questions were included to measure the real alcohol use behaviour, they are 1) Usually, how many drinks did you take every instance you had alcohol during last 30 days? 2) What is the highest amount of drinks you have taken every instance during the last 30 days?

\section{RESULTS}

\subsection{Statistical Analyses: Reliability and Validity of Scales}

Cronbach's Alpha Coefficient was calculated to measure the internal consistency of the items used in the research, It should be above 0.70 to considered as generally satisfactory level (Taber, 2018).

As given in table 01, all the values of items are above the generally satisfactory level.

Root Mean Square Error of Approximation (RMSEA) value less than 0.05 is good, and between 0.05 and 0.08 is satisfactory level, whereas the value is greater than 0.1 is poor ( Fabrigar, MacCallum, \& Wegener, 1999), as given in table 01, all items are higher than the acceptable level.

Table 1. Confirmatory Factor Analysis

\begin{tabular}{|l|l|l|l|l|l|l|l|l|l|}
\hline Variables & Chi-square & RMSEA & GFI & AGFI & CFI & TLI & NFI & AVE & CR \\
\hline Attitudes & 3.321 & 0.052 & 0.922 & 0.853 & 0.822 & 0.856 & 0.845 & .49 & .82 \\
\hline Subjective norms & 3.102 & 0.081 & 0.812 & 0.902 & 0.965 & 0.814 & 0.813 & .54 & .81 \\
\hline $\begin{array}{l}\text { Behavioural } \\
\text { Control }\end{array}$ & 3.102 & 0.054 & 0.953 & 0.924 & 0.971 & 0.858 & 0.916 & .42 & .84 \\
\hline Intention & 3.751 & 0.048 & 0.941 & 0.957 & 0.992 & 0.812 & 0.817 & .51 & .83 \\
\hline Behaviour & 3.441 & 0.053 & 0.937 & 0.981 & 0.943 & 0.874 & 0.864 & .48 & .86 \\
\hline
\end{tabular}

\subsection{Descriptive statistics}

Out of 320 male students, 233 students (72.8\%) reported that they have used alcohol one or two times within last 30 days, and during two to three hours they have taken two to three drinks. Only a few students reported that they took alcohol more than four times within the last 30 days, and during two to three hours they have taken more than four drinks. It indicates that most students use alcohol, however, it is not problematic drinking as quantity and frequency are below the problematic drinking definition. 
Table 2. Mean, Standard Deviation, Bivariate Correlations of study items

\begin{tabular}{llllllllll} 
& Construct & Mean & SD & 1 & 2 & 3 & 4 & 5 & 6 \\
\hline 1 & Alcohol Use & 2.95 & 1.82 & & & & & \\
\hline 2 & Attitudes & 3.82 & 1.76 & $.38^{* *}$ & & & & \\
\hline 3 & Subjective Norms & 3.61 & 1.75 & $.45^{* *}$ & $.45^{* *}$ & & & \\
\hline 4 & $\begin{array}{l}\text { Perceived Behaviour } \\
\text { Control }\end{array}$ & 3.98 & 1.59 & $.35^{* *}$ & $.34^{* *}$ & $.39^{* *}$ & & \\
\hline 5 & Intention & 3.06 & 1.87 & $.43^{* *}$ & $.32^{* *}$ & $.38^{* *}$ & $.31^{* *}$ & \\
\hline 6 & Behaviour & 4.02 & 1.35 & $.34^{* *}$ & $.39^{* *}$ & $.31^{* *}$ & $.39^{* *}$ & $4.12^{* *}$ \\
\hline
\end{tabular}

This study determined to conduct Structural Equation Modelling (SEM) to test the hypotheses

Figure 02 displays the coefficients path analyses of study variables. As figure 02 displays, all the postulated paths were positive and significant, except behavioural control and intention to alcohol use.

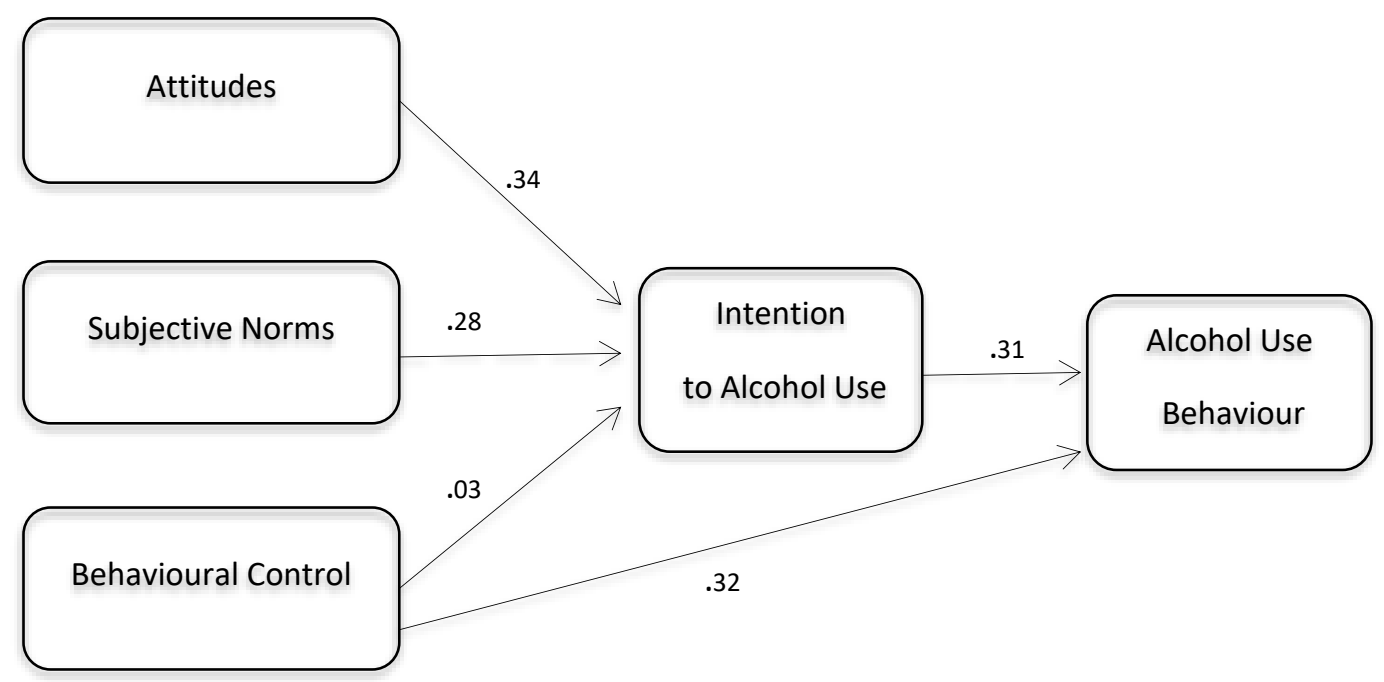

Figure 2. The path analyses of the study variable 
Coefficients path analyses of study variables, attitude $(b=0.34)$, subjective norms $(b=0.28)$ indicate a significant effect on the intention to

use alcohol at the $1 \%$ level $\left(\mathrm{H}_{1} \& \mathrm{H}_{2}\right)$. However, PBC does not indicate a significant impact on intention $(b=0.03)$ to use alcohol $\left(\mathrm{H}_{3}\right)$. Furthermore, Intention towards alcohol use is positively and significantly correlated with alcohol use behaviour $\left(b=0.31, H_{4}\right)$.

\section{DISCUSSION AND CONCLUSIONS}

The objective of this study was to further examine the applicability of the TPB to understand alcohol use among public university students in Sri Lanka. The empirical data analysis backs the TPB domains and previous studies in the field of alcohol use intention and behaviour, indicating that that attitude and subjective norms are significant and positive predictors of alcohol use intention and behaviour. Hypotheses relating to attitudes, and subjective norms to predict intention were significantly and positively supported. These findings are consistent with the previous studies that respondents with a positive attitude towards intention and intention to behaviour, and social norm of alcohol use significantly correlated with alcohol use behaviour (Trafimow, 1996; Wall, Hinson, \& McKee, 1998). Equally, respondence with a negative attitude towards alcohol use as well as who do not consider the social norm of alcohol use have lower intentions to use alcohol and do not perform alcohol use behaviour. Hence, the applicability of the TPB was discovered to be significant predictors of alcohol use behaviour. However, the perceived behavioural control towards alcohol use behaviour was not supported. It was assumed that alcohol use behaviour would be forecasted by intention to alcohol use and behavioural control. Steady with the conclusions of Conner, Warre, \& Cnlos (1999), PBC failed to considerably forecast the alcohol use, whereas intention was significant forecaster alcohol use behaviour. The findings of this study indicate that the relatively high degree of risky alcohol use among university male students. Individual attitude and subjective norms subsidise of university students' intention towards alcohol use. However, perceived behavioural control towards alcohol use behaviour was not supported. Hence, interventions for developing positive attitudes, subjective norms, and behavioural control towards non-use of alcohol could be helpful to reduce alcohol use among university students. There are a few limitations to generalize the finding to the entire university students. The first one is the small sample size of respondents $(N=320)$. The second limitation is that the online data collection method. Questionnaires were sent through google forms and social media. The third limitation is not including females in the study. Therefore, future studies should be undertaken with large and diverse sample size.

Despite the above limitations, this research validates the possibility of TPB in studying the behavioural intention and actual behaviour in a 
different social context. These findings will be important policy implications. For instance, policymakers who wish to reduce alcohol use among university students can introduce interventions targeting to reduce positive attitudes towards alcohol use intention and favourable subjective norms towards reducing alcohol use intention. Correspondingly, policy-makers can propose educational awareness programs to increase the PBC among university students relating alcohol use intention and behaviour. The results indicate the effectiveness of diverse approaches to alcohol reduction programs. It is needed interventions to reduce the intention to use alcohol among university students.

\section{REFERENCES}

Ajzen, I. (1991). The theory of planned behavior. Organizational Behavior and Human Decision Processes, 50(2), 179-211.

Ajzen, I. (2011). The theory of planned behaviour: Reactions and reflections. Psychology \& Health, 26(9), 1113-1127.

Ajzen, I., \& Fishbein, M. (1980). Understanding Attitudes and Predicting Social Behavior. Englewood Cliffs: Prentice-Hall.

Anderson, P., \& Baumberg, B. (2006). Alcohol in Europe a Public Health Perspective. London: Report for the European Commission.

Arria, A., Caldeira, K., Kasperski, S., O'Grady, K., Vincent, K., Griffiths, R., \& Wish, E. (2010).
Increased alcohol consumption, nonmedical prescription drug use, and illicit drug use are associated with energy drink consumption among college students. Journal of Addiction Medicine, 4(2), 7480 .

Baer, J., \& Carney , M. (1993). Biases in the Perceptions of the Consequences of Alcohol Use Among College Students. Journal of Studies on Alcohol, 15(1), 5460 .

Balakrishnan, R., Allender, S., \& Scarborough, P. (2009). The burden of alcohol-related ill health in the United Kingdom. Journal of Public Health, 31, 366-373.

Beaglehole , R., \& Bonita , R. (2009). Alcohol: a global health priority. Lancet, 2173-2174.

Carey, K., Scott-Sheldon, A., Carey, M., Kelly, S., \& DeMartini. (2007). Individual-level interventions to reduce college student drinking: a meta-analytic review. Addictive Behaviors, 32, 2469-94.

Carpenter, R., Fishlock, A., Mulroy, A., Oxley, B., Russell, K., Salter, C., \& Heffeman, C. (2008). After 'Unit 1421': An exploratory study into female students' attitudes and behaviours towards binge drinking at Leeds University. Journal of Public Health, 30, 8 13.

Cheng, T., \& Lo, C. (2015). Change in Adolescents' Alcohol-Use 
Patterns, from Non-Drinking to Non-Heavy Drinking or Heavy Drinking. Journal of Drug Issues, 45(4), 447-459.

Conner, M., Warre, R., \& Cnlos, S. (1999). Alcohol Consumption and the Theory of Planned Behavior: An Examination of the Cognitive Mediation of Past Behavior. Journal of Applied Social Psychology, 29(8), 1676-1704.

Cooke, R., Dahdah, M., Norman, P., \& French, D. (2014). How well does the theory of planned behaviour predict alcohol consumption? A systematic review and metaanalysis. Health Psychology Review, 10(2), 148-167.

Cooke, R., Sniehotta, F., \& Schüz, B. (2007). Predicting binge-drinking behaviour using an extended TPB: Examining the impact of anticipated regret and descriptive norms. Alcohol and Alcoholism, 42, 84-91.

Cooper, M. (1994). Reasons for drinking among adolescents: Development and validation of a four-dimensional measure of drinking motives. Psychological Assessment, 6, 117-128.

Davoren, M., Demant, J., Shiely, F., Ivan, J., \& Perry. (2016). Alcohol consumption among university students in Ireland and the United Kingdom from 2002 to 2014: a systematic review. BMC Public Health, 16, 1-13.
De Silva, V., Samarasinghe, D., \& Gunawardena, N. (2009). Alcohol and tobacco use among males in two districts in Sri Lanka. Ceylon Med J, 54(4), 119-124.

Fabrigar, L., MacCallum, R., \& Wegener, D. (1999). Evaluating the use of exploratory factor analysis in psychological research. Psychological Methods, 4(3), 272-299.

Fishbein, M., \& Ajzen, I. (1975). Belief, attitude, intention, and behavior: An introduction to theory and research. Reading, MA: Addison-Wesley.

Fishbein, M., \& Ajzen, I. (2010). Predicting and changing behavior: The reasoned action approach. New York: Psychology Press.

Gill, J. (2002). Reported levels of alcohol consumption and binge drinking within the UK undergraduate student population over the last 25 years. Alcohol and Alcoholism, 37, 109-120.

Gutiahr, E., Gmel, G., \& Rehm, J. (2001). Relation betwin average alcohol consumption and disease: an overview. Eur Addict Res, 7(3), 117-27.

Harpin, S., Brooks-Russell, A., Ma, M., James, K., \& Levinson, A. (2018). Adolescent marijuana use and perceived ease of access before and after recreational marijuana implementation in 
Colorado. Substance Use and Misuse, 53(3), 451-456.

Hasson, H. (2010). Systematic evaluation of implementation fidelity of complex interventions in health and social care. Implementation Science, 5, 67-75.

Kuntsche, E., Kuntsche, S., Thrul, J., \& Gmel, G. (2017). Binge drinking: Health impact, prevalence, correlates, and interventions. Psychology \& Health, 32, 976-1017.

Liyanage, I., Wickramasinghe, K., Ratnayake, H., Palmer, P., Matthews, D., \& Katulanda, P. (2015). Use of Illicit Substances Among Schoolchildren in Colombo District, Sri Lanka. Substance Abuse, 137-142.

Lo, C., \& Globetti, G. (1993). Partial Analysis of the Campus Influence on Drinking Behavior Students Who Enter College as Nondrinkers. Journal of Drug Issues, 23(4), 715-725.

Lo, C., Howell, R., \& Cheng, T. (2013). Explaining Black-White differences in homicide victimizaion. Aggression and Violent Behavior, 18, 125-134.

McMillan, B., \& Conner, M. (2003). Using the theory of planned behaviour to understand alcohol and tobacco use in students. Psychology, Health and Medicine, 8, 317-328.
Norman, P., \& Conner, M. (2006). The theory of planned behaviour and binge drinking: Assessing the moderating role of past behaviour within the theory of planned behaviour. British Journal of Health Psychology, 11, 55-70.

Norman, P., Bennett, P., \& Lewis, H. (1998). Understanding binge drinking among young people: An application of the Theory of Planned Behaviour. Health Education Research, 13, 163-169.

Oster-Aaland, L., \& Neighbors, C. (2007). The impact of a tailgating policy on students' drinking behavior and perceptions. Journal of American College Health, 56(3), 281-284.

Perera, B., \& Mohammad, T. (2004). Preliminary Study Of Smoking And Alcohol Use Among Students In Southern Sri Lanka. PsychologicalReports, 856-858.

Perkins, H. (2002). Social Norms and the Prevention of Alcohol Misuse in Collegiate Contexts. Journal of Studies on Alcohol, 14, 164-172.

Poonawalla, I., Kendzor, D., Owen, M., \& Caughy, M. (2014). Family income trajectory during childhood is associated with adolescent cigarette smoking and alcohol use. Addictive Behaviors, 39, 1383-1388.

Ranaweera, S., Amarasinghe, H., Chandraratne, $\quad$ N., Thavorncharoensap , M., Ranasinghe, T., \& Karunaratna, S. 
(2018). Economic costs of alcohol use in Sri Lanka. PLoS ONE, 13(6), https://doi.org/10.1371/ journal.pone.0198640.

Somatunga, L., Ratnayake, L., Wijesin, W., Yapa, Y., \& Cooray, M. (2014). National alcohol use prevalence survey in Sri Lanka. Journal of the Postgraduate Institute of Medicine, 1(1), 1-12.

Taber, K. (2018). The Use of Cronbach's Alpha When Developing and Reporting Research Instruments in Science Education (Vol. 48). Cambridge: University of Cambridge.

Trafimow, D. (1996). The importance of attitudes in the predic- tion of college students' intentions to drink. Journal of Applied Social Psychology, 26, 2167-2188.

Wall, A., Hinson, R., \& McKee, S. (1998). Alcohol outcome expectancies, attitudes toward drinking and the theory of planned behavior. Journal of Studies on Alcohol, 59(4), 409-419.

Warren, J., Smalley, K., \& Barefoot, K. (2015). Perceived ease of access to alcohol, tobacco and other substances in rural and urban US students. Rural \& Remote Health, 15(4), 1-10.

Wechsler, H., Lee, J., Kuo, M., Seibring, M., Nelson, T., \& Lee, H. (2002). rends in college binge drinking during a period of increased prevention efforts. Findings from 4 Harvard School of Public Health College Alcohol
Study surveys: 1993-2001. Journal of American College Health, 50, 203-217.

White, A., \& Hingson, R. (2013). The burden of alcohol use: Excessive alcohol consumption and related consequences among college students. Alcohol research: Current reviews., 201-218.

White, H., \& Labouvie, E. (1989). Towards the assessment of adolescent problem drinking. Journal of Studies on Alcohol, 50, 30-37.

WHO. (2014). Global Status Alcohol Report. Geneva: World Health Organization.

WHO. (2018). Global Status Alcohol Report. Geneva: World Health Organization.

Yurasek, A., Merrill, J., Metrik, j., Miller, M., Fernandez, A., \& Borsari, B. (2017). Marijuana use in the context of alcohol interventions for mandated college students. Journal of Substance Abuse Treatment, 79, 53-60.

Zhao, X., White, K., Young, R., \& Obst, P. (2018). Smoking beliefs among Chinese secondary school students: A theory-based qualitative study. Nicotine \& Tobacco Research, 20(3), 321331.

Zimmermann, \& Sieverding, M. (2010). Young adults' social drinking as explained by an 
augmented theory of planned

behaviour: The roles of prototypes, willingness, and gender. British Journal of Health Psychology, 15(3), 561581. 